\title{
Students' experiences and expectations of technologies: An Australian study designed to inform planning and development decisions
}

\author{
Maree Gosper \\ Macquarie University, Australia \\ Janne Malfroy \\ Education Consultant \\ Jo McKenzie \\ University of Technology, Sydney, Australia
}

\begin{abstract}
The pace of technological change accompanied by an evolution in social, work-based and study behaviours and norms poses particular challenges for universities as they strive to develop high quality and sustainable technology-rich learning environments. Maintaining currency with the latest advances is resource intensive, hence the costs incurred in upgrading existing and introducing new technologies need to be carefully weighed up against the potential benefits to students. This calls for a multidimensional approach to planning, with the student voice being an important dimension. Three Australian universities have recently completed a project to gain a better understanding of students' experiences and expectations of technologies in everyday life and for study purposes. The LMS and 25 other technologies ranging from established university offerings (email, learning management systems) to freely available social networking technologies (YouTube, Facebook) were surveyed. More than 10,000 students responded. This paper discusses the development of the survey and presents the broad trends that have emerged in relation to the current use of technologies and desired future use of these for learning purposes. The implications of the survey findings for developing institutional infrastructure to engage students and support their learning are highlighted.
\end{abstract}

\section{Introduction}

Few can deny the pivotal role that information and communication technologies play in facilitating learning and teaching. Most universities support a learning management system (LMS) as part of their standard operating environment. It is not uncommon for the LMS to be extended to include a range of technologies that support specific teaching and learning processes, for example lecture recording technologies, web-based conferencing, collaboration technologies and e-portfolios. While the LMS has been central to the provision of online education, its dominance in recent years has come under question. There are competing views about continued support for large scale centralised LMSs as opposed to more decentralised learning environments (Weller, 2010), stronger engagement in Web 2.0 distributed technologies (Smith \& Borreson Caruso, 2010) and personalised learning environments (Scalter, 2008).

Changing a suite of offerings to accommodate the changing landscape or to simply keep currency with the latest versions of existing technologies needs careful consideration. Substantial costs lie both in developing robust technical infrastructure and in the provision of educational development and support services. Decisions about the technologies to be supported need to be made with clarity regarding the potential benefits to the institution, particularly the benefits for students' learning.

Kuh (2003), in his research on student engagement, warns against universities making judgments about policies and practices in the absence of student engagement data or comparable sources of information. If students are to be placed at the centre of decisions about services and facilities, it is a foregone conclusion that an understanding of their academic and social practices is required (Gibbons, 2007). This is well illustrated through research by Kennedy, Judd, Churchward, Gray, and Krause (2008) on Australian first year university students. They found that the use of technologies was not as widespread as expected, challenging popular assumptions that net generation students display high-levels of digital literacy and interest in the use of information and communications technologies for study purposes. 
Listening to the student voice is essential; responding to that voice is more complex. Implementing new technologies has implications for the entire learning environment (Ellis \& Goodyear, 2010), requiring careful planning, monitoring and evaluation to avoid the possibility of undesirable and unforeseen consequences. Take, for example, the introduction of web-based lecture technologies. Designed to record and deliver live lectures to students in close to real time, these technologies were introduced in response to students' needs and expectations for flexible access to teaching and learning activities (Williams \& Fardon, 2007). Students responded favourably to the introduction of web-based lecture technologies, with rapid uptake and positive student perceptions of their value for learning. However an unforeseen consequence of using these technologies was falling lecture attendance, for which many staff were underprepared (Gosper et al., 2010). Further, web-based lecture technologies have ongoing implications for the campus environment as variable lecture attendance imposes a new set of planning considerations around the optimum mix of physical and virtual teaching and learning infrastructure.

The student voice is an important factor when planning for the development of technologies for learning and teaching, but is not the only one. Institutional culture, technical infrastructure, support services, the skill levels of staff and the capacity to engage in pedagogical change are amongst the other factors for consideration (Bates \& Pool, 2003; Gosper, Woo, Muir, Dudley, \& Nakazawa, 2007). It is within this broader context, that three Australian universities embarked on a project to gain a rich understanding of students' experiences and expectations of technologies for learning in higher education. The rationale underlying this project was to provide an evidence-based student perspective for planning and development of learning technologies and accompanying organisational infrastructure. All three participating universities are metropolitan, campus based universities, with some distance and off-shore teaching.

This paper reports on the development of a cross-institution survey developed as part of the project. Key findings are presented and the implications for university-wide planning and development are discussed.

\section{Survey development}

The aim of the student experiences and expectations of technology (SEET) survey was to identify:

- technologies currently used for work and social purposes

- technologies currently used for study purposes

- technologies that students would like to use more in the future

- $\quad$ satisfaction with services and facilities

- the extent to which experiences and expectations vary across different cohorts of students defined, for example, by discipline grouping, age, gender, level of study, enrolment mode and equity status.

Prior to the development of the SEET survey a review of existing research and survey instruments was undertaken. Two international surveys exploring the student experience of technologies were of particular relevance. The ECAR survey, developed by Educause (Smith, Salaway, \& Borreson Caruso, 2009; Smith $\&$ Borreson Caruso, 2010), gave a perspective on how undergraduates from North American universities think about and use information and communication technologies. It focused on exploring the adoption of technologies for both learning and social purposes. However, the ECAR surveys did not compare current use with expected use. The second survey, the Great Expectations of IT survey (Ipos MORI, 2008), was developed by the Joint Information Systems Committee in the United Kingdom. This survey canvassed first year university students in order to understand their experiences of technology provision in higher education institutions and to gauge how technology affects and changes their experiences of learning, teaching and social/personal interaction.

Although there were similarities in intent, both surveys fell short of fully meeting our survey requirements. For planning purposes we were interested in understanding the perspectives of all students, not just those entering university for the first time. We were also interested in understanding and comparing students' current use of technologies for learning, their preferences for future use, as well their use of the same technologies for social and work purposes. Nevertheless the surveys highlighted relevant issues for consideration and offered opportunities for comparison with the Australian context. To preserve some commonalities with the overseas surveys, they were used as reference points in relation to the scope 
of technologies and issues to be canvassed.

Another key reference point was the Horizon Reports arising from the New Media Consortium's Horizon Project (New Media Consortium, 2012). The annual reports identify emerging technologies likely to have an impact on teaching and learning in universities in a one-, two-, and five-year timeframe. These reports proved to be valuable in ensuring that the SEET survey was forward-looking, capturing emerging trends.

Within the Australian context, research by Kennedy et al. (2008) on incoming first year students at a large research-based metropolitan university offered a local perspective. The target group was 'digital natives' born after 1980 and they explored access to and use of a range of technologies for general and study purposes. Included were web technologies (RSS feeds, podcasts/vodcasts, blogs, social networking), mobile phones, email, hand-held devices (personal digital assistants) and general computing applications (e.g., word processing, multimedia and web development software). They found that although many first year students were highly tech-savvy, the entrenched technologies (e.g., mobile phones and email) remained the most popular, with variable use being made of other technologies. Despite this, students expressed a preference for increasing the use of almost all technologies to support their learning and this was the case whether the technologies were controlled by academics or used on their own volition. We were interested in seeing whether these findings were still current several years later and whether they applied to the wider student population, beyond first year. The findings from the study by Kennedy et al. (2008) were also a reminder of the need to look at a diverse range of technologies in the SEET survey. These technologies included those already established in universities such as library search engines and online resources, learning management systems and email as well as the Web 2.0 social networking and collaborative tools that have appeared in more recent years and are continuing to emerge. We were also interested in understanding whether the use of Web 2.0 in everyday life technologies implied a desire for students to use these for learning purposes.

Knowledge of the online learning and teaching environment at the three universities gained from formal and informal feedback from staff and students was also influential in shaping the SEET survey. For example, at one of the universities, a small ethnographic study of ten students explored how students use technologies in their everyday lives, both on- and off-campus to support their learning (McNeil, Diao, \& Gosper, 2010). This provided useful insights into the choices students were making about technologies as well as the factors and issues underpinning those choices.

Drawing on the above-mentioned sources, the LMS (which was Blackboard at all three universities) and 25 other technologies that were in some use at the three universities were identified for inclusion in the survey:

- $\quad$ instant messaging

- $\quad$ text messaging (SMS)

- email

- collaborative/conferencing technologies (e.g., Skype, Elluminate)

- mobile phones for voice calls

- mobile phones with internet access

- $\quad$ social networking sites (e.g., Facebook, Myspace, Twitter)

- $\quad$ virtual worlds (e.g., Second life, Active worlds)

- blogs

- $\quad$ wikis

- online multi-user computer games

- podcasts/vodcasts (e.g., YouTube)

- $\quad$ social bookmarking/tagging (e.g., del.icio.us, Diigo)

- $\quad$ software used to create audio/video materials (e.g., Audacity, GarageBand, iMovie)

- presentation software (e.g., PowerPoint, KeyNote)

- data analysis software (e.g., spreadsheets, databases)

- Google docs

- e-portfolios

- $\quad$ GPS tagging (e.g., Flickr, Picasa, blogs)

- library search engines

- $\quad$ internet search engines (e.g., Google, Yahoo) 
- $\quad$ RSS feeds

- $\quad$ interactive whiteboards

- $\quad$ web development software (e.g., Dreamweaver, FrontPage)

- $\quad$ tablet computers (e.g., iPad).

Overall, the survey comprised 127 questions organised into five categories. A full list of the questions in all five categories is available at (http://www.mq.edu.au/ltc/altc/student_it_experience). In summary, the first category covered access to computing hardware and the use made of the 25 technologies listed for social and work purposes.

The second category covered the use of technologies specifically for learning. Within this category there were four subsections exploring students' use of the university LMS, other technologies forming part of coursework requirements, technologies to communicate with staff and technologies to communicate with fellow students for learning purposes. Experience has highlighted that the potential of technologies cannot always be judged in isolation from the purpose for which they are to be used. Hence, questions about current and future use were framed in a way that linked technologies with relevant learning activities associated with researching and searching for information, accessing and sharing content, collaborating and communicating, interacting with content and reflecting on outcomes and processes. Some examples are: watch or listen to podcasts or vodcasts created by lecturers; read and comment on blogs created by other students; use RSS feeds to subscribe to information sources that are relevant to your studies; create wikis collaboratively with other students as part of your studies; develop an e-portfolio to record or reflect on your learning as part of your studies; and use web-conferencing or video chat (e.g., Skype, Elluminate, Adobe Connect) to join in remotely to lectures or tutorials.

The third category of questions explored the services and support available to facilitate learning. In developing these questions it was recognised that current student experiences of accessing and using technologies were likely to influence students' forecasts of future use. Factors such as campus infrastructure, skill levels of staff and students and availability of technical support were confirmed in the above-mentioned ethnographic study as being influential in this context. Hence, questions were included to capture information on students' satisfaction with their own skill levels and that of teaching staff in using technologies for learning, the reliability and availability of on-campus technologies and fixtures such as power outlets for charging laptops and other devices, access to wireless networks and IT support services.

The fourth category covered technologies used to receive information and communicate with the university about services and resources (e.g., enrolment status, library fines, tutorial registrations). The final category covered demographic questions to ascertain differences across student cohorts arising from age, gender, disability, background, enrolment modes (internal, external, international, part-time) and employment status. Included also were four open-ended questions to provide richer insights into experiences and preferences for using technologies.

\section{Procedure}

The survey was piloted with 26 students from the lead University, after which questions were refined. Ethics approval was sought and granted through the lead University and then subsequently approved at the two other participating institutions.

The survey was open to all students at the three participating universities and was completed anonymously. It was delivered online to each of the universities through the Voice Project (http://www.voiceproject.com.au/) a legally independent research and consulting company based at Macquarie University. Invitations to participate were extended through the LMS at each participating university and through other regular avenues for student announcements. Incentives to encourage participation included vouchers at Macquarie University, an iPad and vouchers at the University of Western Sydney (UWS) and iPad and shopping vouchers at the University of Technology, Sydney (UTS). The survey was administered during 2010 - in April at Macquarie University, May at UWS and October at UTS. 


\section{Results}

The combined responses from all three universities yielded a data set of 10,269 participants: 1,104 from Macquarie, 7,419 from UWS and 1,754 from UTS. Approximately one quarter of all participants did not provide any demographic information. However, based on the data available each university's demographic profile was reasonably consistent with their university population. Overall there was a higher proportion of:

- females (43.8\% and $31.1 \%$ male)

- $\quad$ those 25 years and under $(54.3 \%, 13.1 \%$ between 26 and 50 years, and $1.5 \%$ over 50$)$

- full-time students $(63.6 \%$, and $11.3 \%$ part-time $)$

- $\quad$ undergraduates $(61.6 \%$ and $13.2 \%$ postgraduate)

All disciplines were represented with stronger representation from business and arts based disciplines which is consistent with the national profiles.

This paper focuses on the broad quantitative findings from the survey, relating to teaching and learning. It does not address administrative uses of technologies or demographic differences between student cohorts. The findings highlighted here provide a picture of trends in current and future uses of technologies from which implications for planning and development of institutional infrastructure and services can be drawn.

\section{Technologies for work and social purposes}

Participants were asked to indicate on a five-point scale how often they currently used the 25 listed technologies in their everyday life for social and work purposes. The scale used throughout the survey was: never or rarely, a few times per semester, a few times a month, a few times a week, or one or more times a day.

The top ten technologies used regularly that is, as a few times a week to one or more times a day, are shown in Figure 1. The most popular was search engines which were used regularly by $93 \%$ of respondents, followed by text messaging (92\%), email $(90 \%)$, mobile phone - voice calls $(83 \%)$, social networking $(77 \%)$, podcasts $(54 \%)$, instant messaging $(51 \%)$, mobile phone with internet $(50 \%)$, library search engines $(36 \%)$ and Google docs $(28 \%)$.

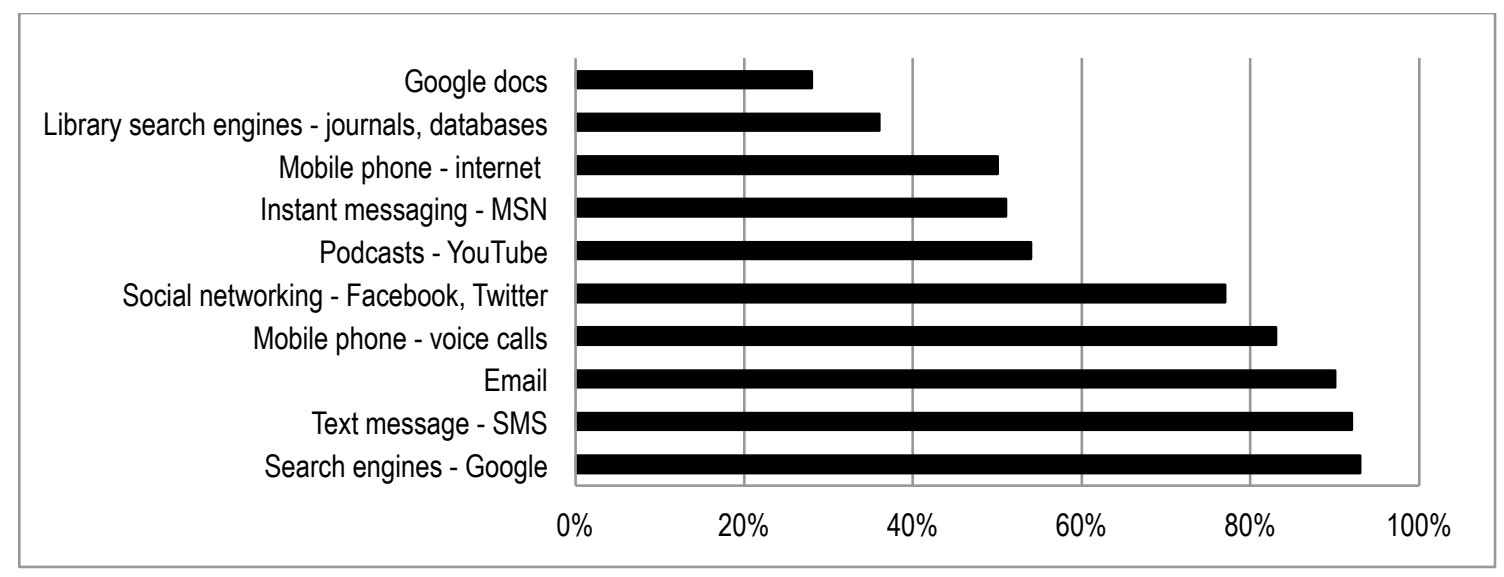

Figure 1. Students' current use of technologies in their everyday life.

The least used technologies were virtual worlds (5\%), web development software e.g., Dreamweaver, FrontPage $(8 \%)$, interactive whiteboards $(8 \%)$, software used to create audio-visual materials e.g., , GarageBand (8\%), social bookmarking and tagging e.g., del.icio.us (9\%). Tablet computers, e.g., iPad, attracted $5 \%$ of use, however data collection was undertaken over the first months of iPad release so this cannot be regarded as a reliable reflection of demand or present use. 


\section{Technologies to support coursework related learning activities}

Twenty five different activities using technologies (other than the LMS) were identified and participants were asked to indicate, how often do you, and how often would you like to, engage in the following learning activities that use technologies as part of your course? The response scales for both items were never or rarely, a few times a semester, a few times a month, a few times a week, or one or more times a day.

Overall, the current engagement with technologies was quite low, except for the use of internet search engines. The top ten technologies used regularly (a few times a week to one or more times a day) are shown in Figure 2 (in black). Internet search engines were used by $90 \%$ of respondents, followed by library search engines (46\%), social networking sites for group work activities $(24 \%)$, podcasts/vodcasts created by lecturers $(23 \%)$, web tools e.g., Google docs to work collaboratively (16\%), mobile phones e.g., iPhone to access information (13\%), web services to share resources e.g., Flickr, YouTube (12\%), blogs to read and comment (9\%), student podcasts (9\%) and RSS feeds (9\%). The remaining technologies canvassed had usage rates between $8 \%$ and $4 \%$ and these included use of Garage Band/iMovies to create media files, creating blogs, web services to share information (Flickr, YouTube), wikis, virtual worlds, eportfolios, web conferencing (via Skype and Adobe Connect), HTML editors, interactive whiteboards and tablet PCs.

When the top ten technologies were matched with participants' preferences for future use (shown in grey in Figure 2) it can be seen that students would like to make more use of all technologies, except internet search engines. Search engines already attract high use, which could explain why students are not looking to make more use of them in the future. Two other technologies, not shown in Figures 1 or 2, that students would also like more use made of were tablet computers, e.g., iPads and interactive whiteboards. Fortyfive percent and $33 \%$ of students, respectively, would like to use these at least a few times a week.

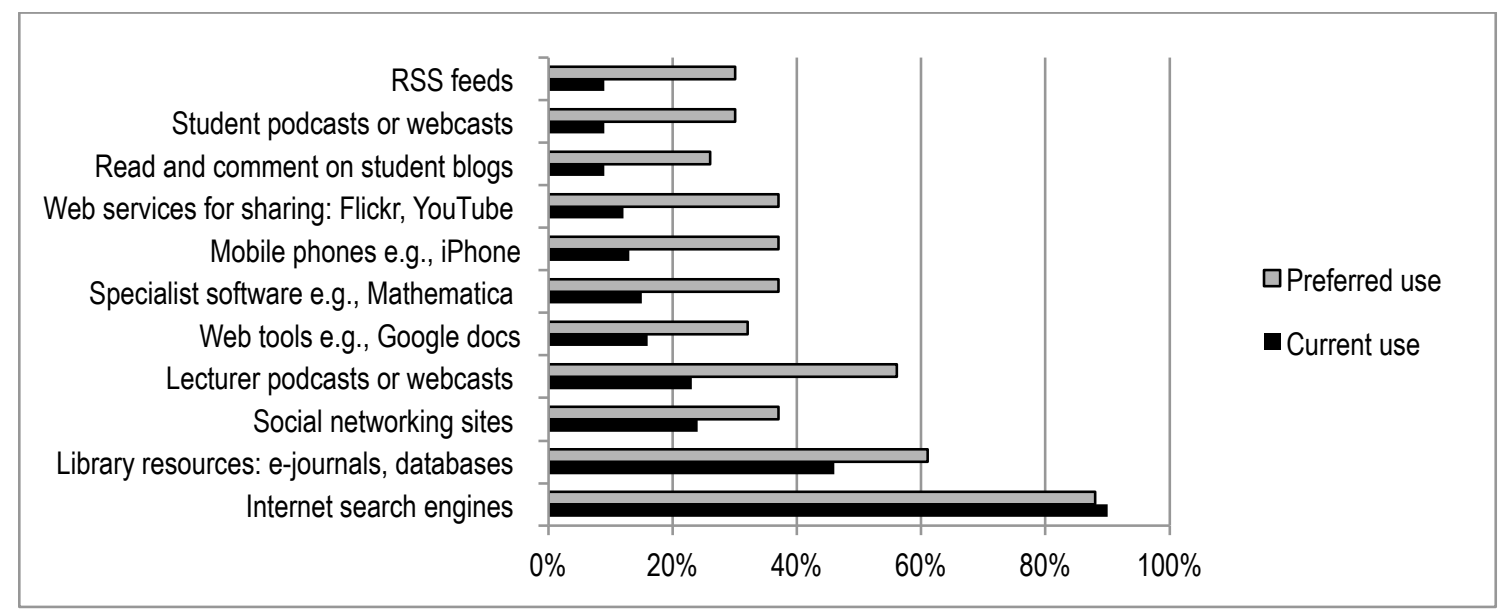

Figure 2. Students' current versus preferred use of technologies for learning as part of course requirements.

There is quite a lot of speculation about the use of freely available social networking tools and other Web 2.0 technologies for educational purposes. We were particularly interested in understanding whether the use of these technologies in everyday life translates into a desire for use as a tool for learning. When everyday use of these technologies was compared with students' forecasts of these technologies' potential for learning, the results, as shown in Figure 3, were mixed. The Web 2.0 technology most frequently used in everyday life (shown in black) is social networking, with $77 \%$ of respondents using social networking technology at least a few times a week. When asked about preferences regarding the future use of social networking technologies for learning purposes, only $37 \%$ of students indicated they would like to do so on a regular basis. Students clearly do not currently perceive social networking technologies as having strong potential for educational purposes. A similar but weaker pattern was evident for wikis, with $26 \%$ of students indicating they use wikis at least a few times a week for everyday purposes but only $17 \%$ 
would like to use them in the future for learning.

In everyday life, little use is made of virtual worlds (5\%), tagging (9\%), e-portfolios (14\%), blogs (16\%) and RSS feeds (18\%), with somewhat more use being made of Skype/Elluminate (22\%), Google docs $(26 \%)$ and podcasts $(54 \%)$. However these technologies are seen to have some educational value and students would like more use made of them in the future.

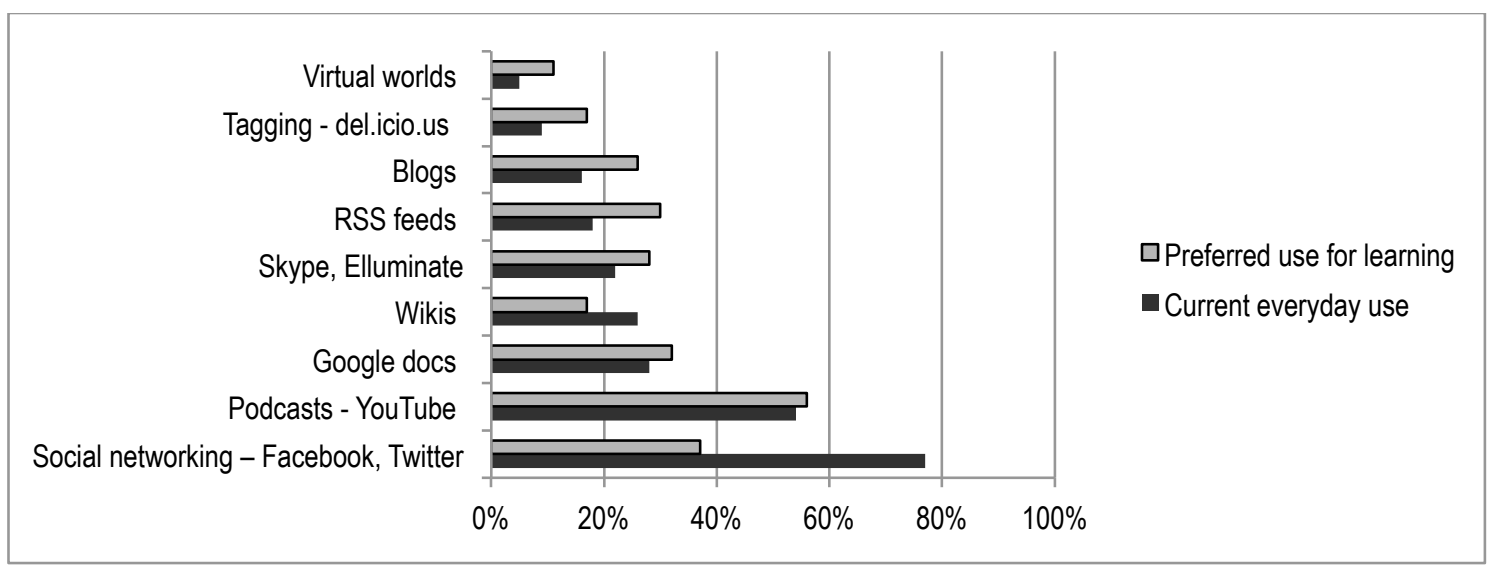

Figure 3. Students' current use of Web 2.0 technologies for everyday use versus their preferred use of these technologies for learning as part of course requirements.

\section{The tools and functions in the LMS}

A comparison of current and future use of LMS tools is shown in Figure 4. The most commonly used LMS functions (shown in black) were accessing online content and reading announcements that appear at login, with $56 \%$ of participants doing so on a regular basis. The use of LMS tools and functions in order of popularity were:

- $40 \%$ accessing unit outlines

- $37 \%$ accessing lecture recordings

- $36 \%$ taking part in discussions

- $28 \%$ doing quizzes for assessment

- $26 \%$ tracking progress and grades

- $22 \%$ using mail

- $19 \%$ doing quizzes for feedback

- $17 \%$ submitting assignments

- $14 \%$ receiving returned assignments

- $13 \%$ sharing work with other students.

In the future (shown in grey), students would like more use made of all LMS tools and functions. The strongest demand is for lecture recordings, with an increase of $27 \%$ followed by assignment submission $(23 \%)$, quizzes for feedback (21\%), tracking grades and progress (21\%), return of assignments $(19 \%)$ and discussions (18\%). 


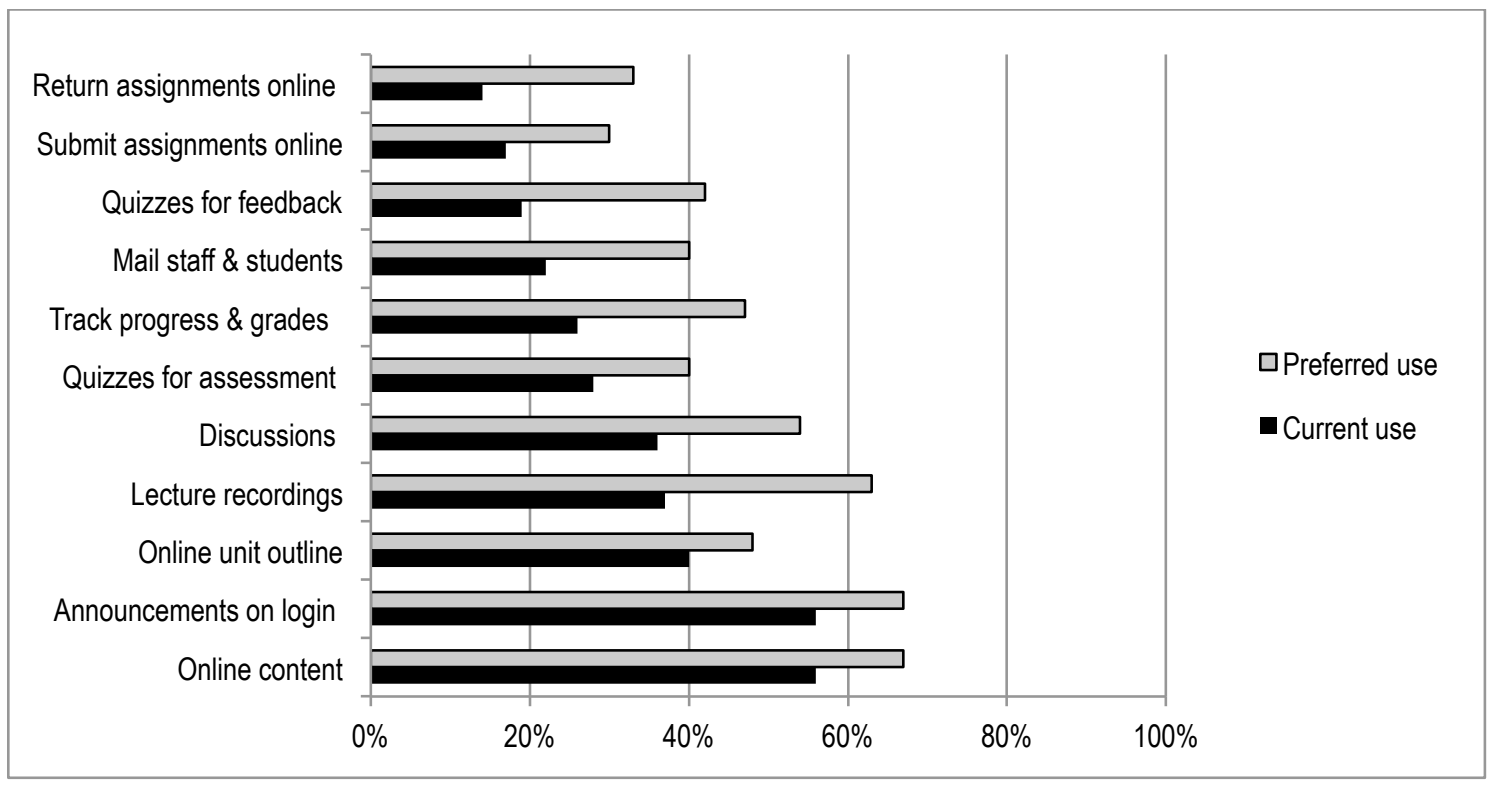

Figure 4. Students' current and preferred use of LMS tools and functions.

Overall, when comparing the differences between students' current use and their preferred use of all technologies for coursework activities the strongest interest is for:

- $\quad$ tablet PCs (e.g., iPads) to access and contribute to activities with a difference between current use and preferred future use of 37 percentage points

- $\quad$ podcasts/vodcasts developed by lecturers - 33\%

- $\quad$ interactive whiteboards to participate in tutorial based learning activities $-27 \%$

- lecture recordings delivered through the LMS - 26\%,

- mobile phones to access and contribute to study-related information on the Internet $-24 \%$

- $\quad$ LMS quizzes for feedback - $23 \%$

- web-conferencing (e.g., Skype/Elluminate) to join in remotely with lectures or tutorials $-22 \%$

- $\quad$ LMS tools for tracking progress $-21 \%$

- $\quad$ podcasts prepared by students $-21 \%$

- RSS feeds to subscribe to information and resources $-21 \%$

\section{Technologies for communication between staff and students for learning purposes}

The use of technologies for communicating with staff and fellow students for learning purposes were treated separately because of the different levels of choice available. For instance, communication with staff is largely dictated by staff preferences, whereas students have greater flexibility and choice in the technologies they use when communicating with each other.

Current and preferred technologies for communicating with staff are shown in Figure 5 and for communicating with fellow students in Figure 6. Overall, it can be seen that students would like more opportunities for communicating with both staff and fellow students, regardless of the type of technology involved. Nevertheless there are some clear preferences. Email, communication via the LMS (Blackboard), and face-to-face communication are the most popular means of communicating with staff, both now and in the future.

Top preferences for communication with fellow students, now and in the future, were face-to-face, text messaging using SMS and email. Overall when students communicate with each other, as opposed to staff, they make more use of face-to-face contact and social networking technologies and less use of the LMS. However, the LMS rates fourth in their preferences for future use. 


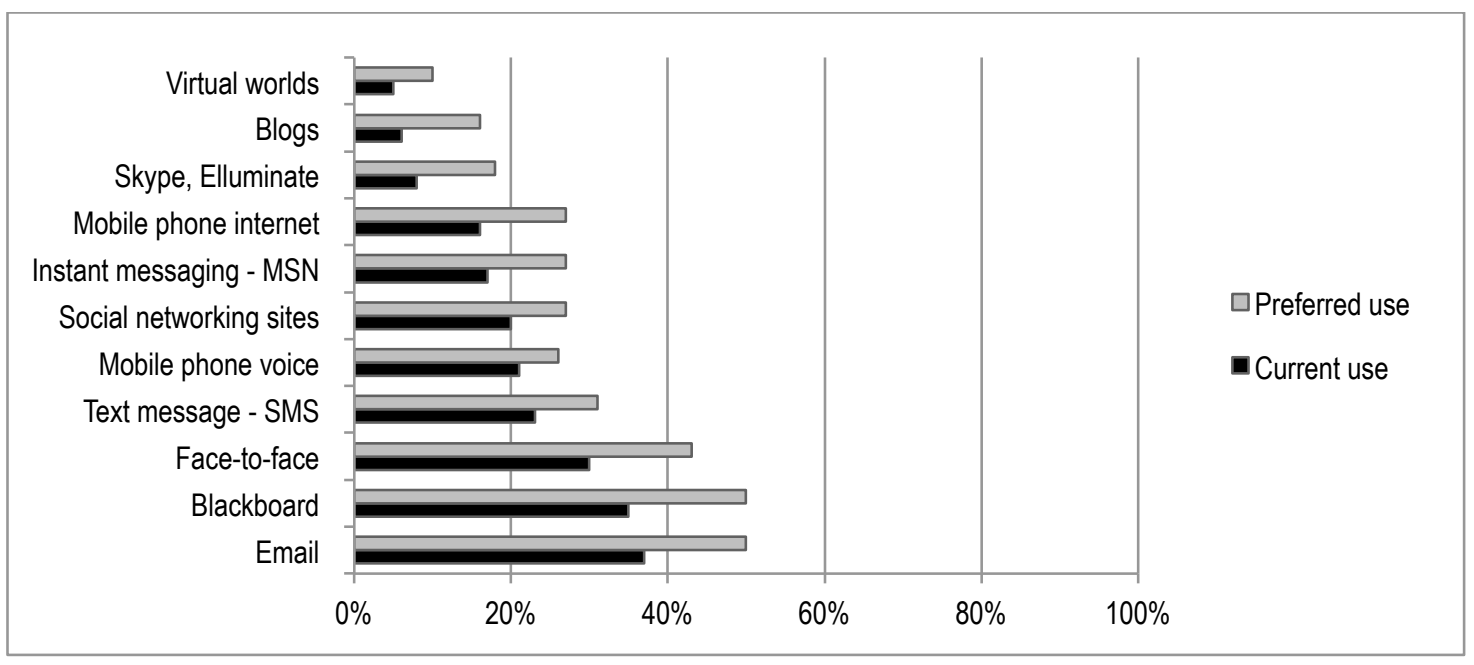

Figure 5. Student communication with teaching staff in their course.

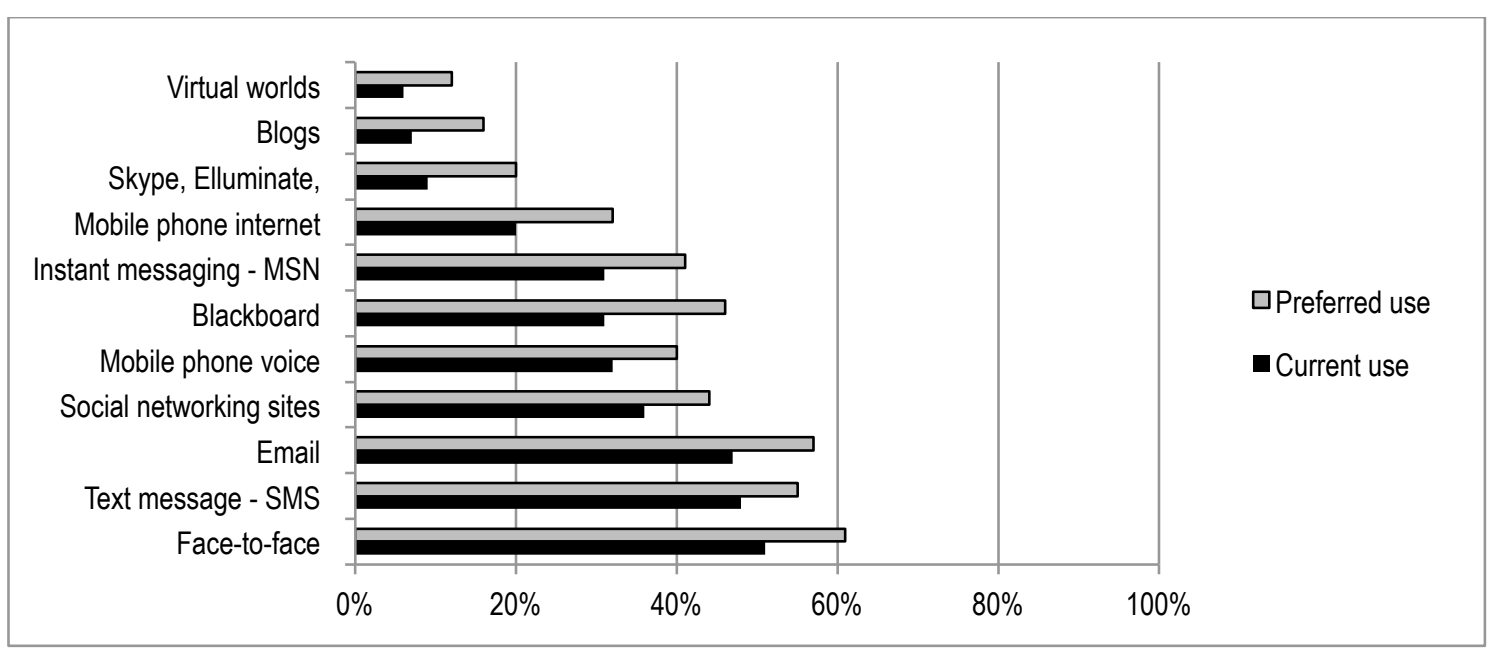

Figure 6. Student communication with other students for learning purposes.

\section{Discussion and implications for planning and development}

This research aimed to support institutional planning for technologies by providing insights into the ways students are currently using technologies for everyday purposes and for learning as well as their future preferences.

Findings from the survey indicated that students are well connected, with $85 \%$ of the 10269 students surveyed having access to a laptop computer, 67\% having a desktop computer at home, just over half (51\%) having access to a mobile phone with an internet connection and $45 \%$ having access to a laptop with an internet connection on-campus. This level of access, as well as the extensive use being made of search engines, email and social networking in their everyday lives, indicates that students are well placed to take advantage of technologies to support their learning. Indeed, the results of the SEET survey suggest that students have a clear expectation that technologies will be integral to their university experience. The blend of face-to-face and eLearning has enabled the flexibility sought by students to balance the competing priorities in their lives (Lefoe \& Hedberg 2006; Sharpe, Benfield, Roberts, \& Francis, 2006).

Our findings are similar to those of Kennedy et al. (2008) in that we found students' uses of technologies for everyday purposes centred on well-established technologies. Over three-quarters of students regularly use search engines, text messaging (SMS), email, mobile phones (without internet) and social networking, 
with around half using podcasts, mobile phones with internet connections and instant messaging. Use of other technologies was relatively low, indicating that the most popular technologies are those that have been around for some time, are efficient, reliable and easy to use - all factors which have been shown to be important for continued use (Collis \& Moonen, 2004).

A similar, somewhat conservative pattern was evident for educational use. We found that the technologies that are currently used most often for coursework related learning activities are internet search engines, library databases and journals. The LMS still remains popular, particularly for accessing course information and content (including lecture recordings) and for communicating with staff and fellow students. There is also strong demand for functions that provide feedback, particularly quizzes for formative purposes and tools for tracking progress. Overall, students would like to make more use of almost all technologies to support their learning, with the exception of internet search engines (e.g., Google, Yahoo) however these already have very high levels of use for both every day and learning purposes.

With regard to communication for learning purposes, students are currently making use of all technologies to some degree however, once again, the more entrenched technologies dominate. Email, the LMS, face-to-face communication, and to a lesser extent SMS messaging, are the technologies preferred by students for communicating with staff. To some extent, communication pathways between students and staff are predetermined by staff preferences. Even though there is more freedom of choice when it comes to communicating with fellow students, the same technologies prevailed. The main difference between staff-student and student-student communication was the appearance of social networking for the latter. Also noteworthy is the preference shown by students for continued and increasing use of the LMS for communicating with staff and also with each other. Current and projected demand for virtual worlds, blogs, and web-conferencing was minimal.

While students clearly signified that they wanted greater use made of existing mainstream technologies, there is also some indication that the status quo was not fully meeting their expectations - $61 \%$ of students were satisfied with the range of technologies available for studying and communicating and $62 \%$ were satisfied with current opportunities to use their chosen technologies for studying and communicating. While these relatively low satisfaction levels suggest the need to broaden the range of technologies available, the challenge is in identifying what those technologies should be.

Our research suggests it cannot be assumed that the technologies students use for work and social purposes are the same technologies that students see as useful for educational purposes. We found that students are quite strategic in their use of technologies and do not necessarily want to use new or different technologies simply because they are available; it is the perceived value that technologies can add to their learning experience that is seen as important. This is exemplified by social networking technologies that are popular for everyday use, with $77 \%$ of students using these on a regular basis. However, only $37 \%$ of students would like more use made of these technologies for coursework activities in the future and even fewer students $(27 \%)$ see social networking technologies as useful for communicating with staff. While student-staff communication via social networking technologies is likely to be orchestrated by staff and this could influence uptake, low projection for future use of such technologies was also evident in situations with students in control; only $44 \%$ of students would like more use of social networking technologies when communicating with each other about learning related issues. Clearly, students see these technologies as social, rather than educational, tools. This finding is supported by other research conducted at a similar time. Jones, Blackey, Fitzgibbon, and Chew (2010), in a study across four universities, found that students thought Facebook was more useful for social rather than teaching purposes - although Facebook was sometimes used informally for learning purposes. Moreover, research by Madge, Meek, Wellens, and Hooley (2009), on first year campus-based undergraduate students studying at a British University, suggests a distinct divide between learning and personal spaces.

This is not the case for all Web 2.0 technologies with RSS feeds and blogs in particular being seen as having much greater value for educational rather than for social and work purposes. Based on the relative differences between current and preferred future use, other technologies that students identified as having the most potential (outside tools and functions of the LMS) are: 
- video and audio resources - lecture recordings, podcasts/vodcasts developed by both lecturers and students

- mobile technologies (tablet PCs, iPads)

- tools to promote connectedness and interaction - interactive whiteboards, web-conferencing and RSS feeds.

These findings conform to predictions emerging from recent New Media Consortium (2012) reports.

Turning potential into reality requires careful and comprehensive planning. Simply capitalising on new technologies is not enough for successful transformation of potential; new pedagogical models and services are needed in order to engage students (Johnson, Adams, \& Cummins, 2012). This calls for the ongoing professionalization of staff to ensure that they have the requisite knowledge and skills to effectively integrate new technologies into the curriculum. Herein lies a challenge as we found that students perceived staff to be somewhat lacking in technological skill. While $82 \%$ of students were satisfied with their own skill level in using technologies, only 59\% were satisfied with the level of technology skills among teaching staff. Moreover, only $61 \%$ of students agreed that the way the technologies were currently being used enhanced their learning experience. Jones et al. (2010) reported similar student perceptions. Based on a study of social networking in higher education they found that, in general, students felt staff were not up-to-date and did not know how to make effective use of new technologies. If the full potential of technologies is to be exploited, then academics must have the skills to be able to use technologies effectively. Technical skills alone will not necessarily lead to effective learning; an understanding of how students learn is also needed. As Ellis and Goodyear (2010) point out, instructors who have a richer understanding of how students learn are better able to make informed choices about which technologies to use and how to effectively integrate these into the curriculum.

In support of general claims that people expect to be able to work, learn and study whenever and wherever they want (Johnson, Smith, Willis, Levine, \& Haywood, 2011) the findings revealed that students are indeed engaging in their studies from a variety of locations: $97 \%$ of survey participants were accessing technologies for study at home, $25 \%$ at work and $34 \%$ from any location using mobile technologies. In addition, $65 \%$ of participants used technologies on campus either via campus-based facilities or other mobile technologies, with $45 \%$ having access to laptops with internet connections. Although all three universities have been upgrading and extending their infrastructure, demand for facilities and services is outstripping supply. This is placing strain on the infrastructure and we found that less than $52 \%$ of students were satisfied with the reliability of the technology on campus, spaces provided for using mobile technologies or other devices and the availability of wireless networks, power outlets to charge laptops and other electronic devices.

Technology generates high expectations and high expectations correlate with high costs (Ingerman \& Yang, 2011). Managing expectations is an ongoing challenge for universities, particularly when faced with the twin challenges of providing high-quality services and controlling costs (Johnson et al., 2011). With high levels of student connectedness and the increasing availability of a sophisticated array of webbased tools that are affordable and easy to use, it is questionable whether it is feasible, or necessary, for universities to cater for all possible uses of learning technologies. Creating an environment which supports the notion of "bring your own device" could be liberating for both students and the university. On the one hand, students would no longer be limited to the tools and technologies provided by their university, opening the way to capitalise on the affordances of web-based technologies to augment their learning in ways that suit their own contexts and needs. On the other hand, universities could then concentrate their scarce resources on the provision of core technologies and infrastructure to support a highly mobile and connected student cohort. Such an approach calls for a new conceptualisation of the way universities plan for the development of technology rich learning environments.

The findings from this research suggest a new multidimensional approach to planning comprised of three different levels of technology provision: institutionally supported technology provision, academic-led technology provision and student-led technology provision. The levels are defined not so much by the attributes of technologies themselves, but by the ways technologies are used by staff and students. Each level implies specific considerations affecting university-wide planning and development, campus-wide infrastructure and teaching and learning support strategies to optimise the effectiveness of technologies. 


\section{Institutionally supported technology provision}

Institutionally supported uses of technologies comprise mainstream technologies that are used widely by both staff and students. Learning management systems, lecture recording systems, library search engines and online resources are examples of the institutionally supported technologies covered by the SEET survey. These technologies are core enterprise systems essential to the delivery of educational programs both on and off campus. As such, they need to be securely integrated into campus infrastructure, institutional policy and quality assurance frameworks to ensure a robust and secure environment that is accessible to all students and staff. High levels of interoperability with other enterprise systems (e.g., human resources, student administration and library systems), and the provision of training and support services and professional development programs are associated with this level of provision. Institution-led provision of technologies is resource intensive requiring dedicated funding for regular system maintenance and ongoing development. Further, high levels of resourcing are necessary in order to ensure that staff and student expectations are met including seamless access, 24/7 availability of support for both on campus students and those in remote locations.

Our findings strongly endorse continued institutional support for core, mainstream technologies for the foreseeable future. Nevertheless, this does not imply continuation of the status quo; a suitable mix of technologies at the institutional level requires constant review to ensure that technologies are fit-for purpose. Planning decisions will therefore need to accommodate and support innovation, the introduction of new technologies and the retirement of outmoded technologies. Our research suggests that support for the mainstream technologies should not exclude exploration of other technologies. Students identified a need for greater diversity in technologies to suit specific needs and the next two levels of technology provision address the provision of a more diverse set of technologies.

\section{Academic-led technology provision}

Academic-led uses of technologies encompass technologies that are not widely used across the university but are employed by faculties or individual academics within their own disciplines to support different aspects of teaching and learning. Examples of such technologies covered in the SEET survey include whiteboards, podcasts of lectures and web-conferencing (via Skype, Elluminate and Adobe Connect). The defining feature of these technologies is that they are not widely used across the university but are either relatively stable discipline specific technologies (e.g., Mathematica, AutoCAD, whiteboards and various web-based applications) or fall under the umbrella of innovative technologies that are being trialled to ascertain their future potential (e.g., iPADS and wikis).

For learning and teaching purposes the use of technologies at this level is at the behest of staff. Moreover, the way in which these technologies are integrated into the curriculum and used to support learning will depend on the knowledge and skills of staff. Because these technologies are teacher-led they can be regarded as part of standard university offerings, therefore provision of safe, secure and accessible environments for the use of such technologies is necessary. It is also incumbent upon the university to build the capability of staff to feel confident in evaluating the potential of new technologies and exploring new pedagogical approaches.

University-wide planning implications in this context extend to ensuring that campus infrastructure can serve discipline-specific requirements as well as innovative uses of technologies. The boundaries between centralised and faculty level responsibilities will vary depending on the technologies themselves and the extent to which these are being used. Hence planning involves understanding the responsibilities for resourcing and implementing different technologies and the scope of activity encompassed by various technologies. However, at a minimum, effective planning will require arrangements for the integration of technologies into technical and academic campus infrastructure, ensuring compliance with policy frameworks, student support and training, and professional development to facilitate innovation and pedagogical change.

\section{Student-led technology provision}

Student-led uses of technologies extend to technologies that are freely available and independent of the university. Examples of such technologies surveyed include social networking, internet search engines, RSS feeds and Google docs. The key feature of these technologies is that they are sourced and used at students' own volition. The resourcing implications for the university of using such technologies are 
minimal compared to the other two levels of technology provision. However, student-led technology use has implications for planning from two perspectives. The first is that of infrastructure provision to enable connectivity to internet services and mobile devices as well as well-appointed informal learning spaces for students to work, communicate and collaborate. The second relates to ensuring the responsible use of these technologies. Policies and guidelines, training for students and professional development for staff are amongst the range of mechanisms that need to be put in place to raise awareness of the issues and implications associated with their use.

The preceding discussion has not fully explored all planning implications for the university of technology provision; rather the intent was to provide a broad overview based on the findings emerging from this research. More work is needed to develop a comprehensive profile of the three levels of technology provision within individual universities to capture their unique contexts as defined by their visions for teaching and learning and their specific organisational arrangements for implementing learning technologies.

\section{Conclusion}

The increasing range of technologies available combined with the limited financial resources of universities generally means that most universities in Australia are developing strategic business plans for provision of learning and teaching technologies. With regard to developing such plans Stiles (2004) notes that:

Clearly understanding where you are starting from is as important as understanding where you want to get to. Expanding the use of eLearning in an institution requires a clear and honest analysis of the organisation in terms of strengths and weaknesses viewed against its strategic goals. (p. 14)

The SEET survey was designed specifically to capture students' perspectives of their current technology experience and their expectations of learning technologies in the future. A unique feature of the survey is that it differentiated between students' uses of technology for everyday work, social purposes and educational purposes. While the insights gained from the survey echo some of the findings and forecasts emanating from international studies, the more nuanced local perspective provided by the SEET survey enables Australian universities to plan for the future with confidence, knowing that their plans will reflect the capabilities, needs and aspirations of their own students.

The multilevel planning framework presented for capturing the different uses of technologies within the university offers a new way of conceptualising and making sense of a very complex environment. It offers a model for planning in relation to variable requirements in terms of technical infrastructure, support and professional development services and other organisational factors necessary to achieve a high quality, technology-rich learning environment. The multilevel planning framework is a work in progress and there is opportunity for future research to explore the general applicability of this framework.

Change is inevitable, both in relation to technologies that are available and the integration of these into the fabric of our lives. The SEET survey has given a snapshot of broad trends in the current experiences and expectations of students. Further analysis is taking place, exploring the use of the LMS and differences between student cohorts (e.g., disciplinary groups, low SES students, international, distance and on-campus students, age and gender). There is also potential for repeated use of the survey to provide a longitudinal data set for monitoring trends and identifying technologies with fleeting popularity, as well as those with serious potential as tools for learning.

\section{Acknowledgements}

We would like to acknowledge Dr Peter Langford from Voice Project for his advice on the development of the survey and for the survey delivery at each of the Universities. Feedback from colleagues on the early drafts of the SEET survey is also greatly appreciated. 


\section{References}

Bates, A.W., \& Poole, G. (2003). Effective teaching with technology in higher education. San Francisco, CA: Jossey-Bass.

Collis, B., \& Moonen, J. (2004). Will they use it? In B. Collis \& J. Moonen (Eds.), Flexible learning in a digital world. London and New York: Routledge Falmer.

Ellis, R., \& Goodyear, P. (2010). Students' experiences of e-learning in higher education: The ecology of sustainable innovation. London: Taylor and Francis.

Gibbons, S. (2007) Redefining the role of information professionals in higher education to engage the net generation. Paper presented at EDUCAUSE Australia, Melbourne April 29 - May 2. Retrieved from http://www.caudit.edu.au/educauseaustralasia07/authors_papers/Gibbons2.pdf

Gosper, M., McNeill, M., Phillips, R., Preston, G., Green, D., \& Woo, K. (2010). Web-based lecture technologies and learning and teaching: A study of change in four Australian universities. ALT-J Research Special Issue on the Transformational Impact of Learning Technology, 18(3), 251-263.

Gosper, M., Woo, K. Muir, H., Dudley, C., \& Nakazawa, K. (2007). Selecting ICT-based solutions for quality learning and sustainable practice. Australian Journal of Educational Technology, 23(2), 227247.

Ingerman, B., \& Yang, C. (2011). Top 10 IT Issues 2011. EDUCAUSE Review, 46(3), 26-40.

Ipsos MORI (2008). Great expectations of ICT: How higher education institutions are measuring up. Joint Information Systems Committee (JISC). Retrieved from http://www.jisc.ac.uk/publications/research/2008/greatexpectations.aspx

Johnson, L., Adams, S., \& Cummins, M. (2012). The NMC Horizon Report: 2012 Higher Education Edition. Austin, TX: The New Media Consortium.

Johnson, L., Smith, R., Willis, H., Levine, A., \& Haywood, K. (2011). The 2011 Horizon Report. Austin, TX: The New Media Consortium.

Jones, N., Blackey, H., Fitzgibbon, K., \& Chew, E. (2010). Get out of MySpace! Computers and Education, 54(3), 776-782.

Kennedy, G., Judd, T., Churchward, A., Gray, K., \& Krause, K. (2008). First year students' experiences with technology: are they really digital natives? Australasian Journal of Educational Technology, 24(1), 108-122.

Kuh, G. D. (2003). What we're learning about student engagement issues. Change, 35(2), 24-32.

Lefoe, G. \& Hedberg, J. (2006). Blending on and off campus: a tale of two cities. In C. Bonk \& C. Graham (Eds.), Handbook of blended learning environments: global perspectives, local designs, (pp. 325-337). San Francisco, CA: Pfeiffer.

Madge, C., Meek, J., Wellens, J., \& Hooley, T. (2009). Facebook, social integration and informal learning at university: it is more for socialising and talking to friends about work than for actually doing work. Learning, Media \& Technology, 34(2), 141-155.

McNeill, M., Diao, M. M., \& Gosper, M., (2011) Student uses of technology in learning: two lenses. Interactive Technology and Smart Education, 8(1), 517.

New Media Consortium (2012). Austin, TX. Retrieved from http://www.nmc.org/horizon 
Scalter, N. (2008). Web 2.0, personal learning environments, and the future of learning management systems. ECAR Research Bulletin, 8(13) 13pp. Retrieved from http://net.educause.edu/ir/library/pdf/ERB0813.pdf

Sharpe, R., Benfield, G., Roberts, G., \& Francis, R. (2006). The undergraduate experience of blended elearning: a review of UK literature and practice. The Higher Education Academy. Retrieved from http://www.heacademy.ac.uk/assets/York/documents/ourwork/research/literature_reviews/blended_el earning_full_review.pdf

Smith, S. D., \& Borreson Caruso, J. (2010). The ECAR Study of undergraduate students and information technology, 2010 - key findings. Boulder, CO: EDUCAUSE Center for Applied Research. Retrieved from http://www.educause.edu/Resources/TheECARStudyofUndergraduateStu/217334

Smith, S. D., Salaway, G., \& Borreson Caruso, J. (2009). The ECAR study of undergraduate students and information technology. Boulder, CO: ECAR, EDUCAUSE Center for Applied Research. Retrieved from http://www.educause.edu/ers0906

Stiles, M. (2004). Is an eLearning strategy enough? Educational Developments, 5(1), 13-15.

Weller, M. (2010) The centralisation dilemma in educational IT, International Journal of Virtual and Personal Learning Environments, 1(1), 1-9.

Williams, J., \& Fardon, M. (2007). Recording lectures and the impact on student attendance. Paper presented at the ALT-C, September $4-6$, Nottingham, UK.

Corresponding author: Maree Gosper, maree.gosper@mq.edu.au

Australasian Journal of Educational Technology (C) 2013.

Please cite as: Gosper, M., Malfroy, J., \& McKenzie, J. (2013). Students' experiences and expectations of technologies: An Australian study designed to inform planning and development decisions. Australasian Journal of Educational Technology, 29(2), 268-282. 